McConaghy, N. (1969). 'The place of behaviour therapy in the treatment of anxiety.' Australian and New Zealand Journal of Psychiatry, 3, No. 3A, 293-8.

Overall, J. E., Hollister, L. E., Mryer, F., Kimbell, I. Jr., and Shelton, J. (1964). 'Imipramine and thioridazine in depressed and schizophrenic patients. Are there specific antidepressant drugs?' Journal of the American Medical Association, 189, 605-8.

Rickels, K., RaAb, E., and Carranza, K. J. (1965). 'Doctor medication guesses: an indicator of clinical improvement in double-blind studies.' fournal of New Drugs, 5, 67-7r.

\section{FOLLOW-UP OF DAY PATIENTS}

\section{DeAR Sir,}

In an article published two years ago, R. S. Ferguson ( 1 ) refers to the absence in the literature of follow-up studies, controlled or otherwise, of daypatients in this country, nor do recent publications mention any such study $(2,3)$. I am glad to hear that Dr. Ferguson (4) has undertaken further researches and look forward to seeing it in print.

In the Psychiatric Day Department at Crumpsall Hospital, Manchester, out-patients are also seen by the two psychiatrists responsible for the day-patients. These out-patients constituted a control group, as the decision whether to admit as day-patients frequently rested on practical rather than clinical considerations; though it must be said that younger patients currently off work because of their psychiatric illness usually became day-patients, indicating perhaps a somewhat greater degree of illness in the latter, who comprised one-third of all the daypatients followed up. We sent questionnaires to all day-patients and out-patients discharged in the past four years. The questionnaires were identical except for the word 'day-patient' or 'out-patient' respectively, and a second form was included on which the nearest relative was asked to make an independent assessment. No name was to be entered on the questionnaires, which were thus returned anonymously. Patients and relatives were asked to tick on a fivepoint scale: (1) clinical improvement; (2) residual handicap at work caused by the psychiatric complaint for which they were treated; (3) handicap in patients' social life, and (4) in their family relationships. Further, patients and relatives were asked to assess on a three-point scale the treatment received in our department as day or out-patient, compared to other treatment they might have undergone for the same complaint elsewhere, before or since. Breakdown for age, sex and diagnosis for the two groups circularized showed that there was no significant difference in their composition. Organic psychosyn- dromes and psychogeriatric day-patients were excluded.

There was a marked discrepancy in the proportion of completed forms returned, the day-patients enabling us to analyse 66.5 per cent of questionnaires sent out, but the corresponding figure for out-patients was only $40 \cdot 9$ per cent. This is partly explained by urban clearance in North Manchester having reached its maximum by the time out-patients were circularized.

There was no significant difference in the percentage of true defaulters, but the percentage of those who returned inadequately completed forms (4.6 per cent of day-patients and 12.5 per cent of out-patients) was significantly greater $(p=0.05)$ in out-patients.

Scrutiny of completed questionnaires revealed that answers given by patients and their relatives differed so little that it was assumed they co-operated in most instances, and we felt justified in averaging the small discrepancies where they did occur. The table shows percentage of patients recovered plus those greatly improved:

\begin{tabular}{|c|c|c|c|}
\hline & & $\begin{array}{l}\text { Recove } \\
\text { greatly }\end{array}$ & $\begin{array}{l}\text { red plus } \\
\text { improved }\end{array}$ \\
\hline & & $\begin{array}{c}\text { Day- } \\
\text { patients }\end{array}$ & $\begin{array}{c}\text { Out- } \\
\text { patients }\end{array}$ \\
\hline $\begin{array}{l}\text { In their clinical condition } \\
\text { In their work (including }\end{array}$ & . & $68 \%$ & $70 \%$ \\
\hline housework) .. & & $64 \%$ & $71 \%$ \\
\hline In their social life & $\cdots$ & $54 \%$ & $64 \%$ \\
\hline In their family relationships & $\ldots$ & $60 \%$ & $64 \%$ \\
\hline Numbers analysed & .. & 115 & 72 \\
\hline
\end{tabular}

There was no significant difference between the two groups, and equally the 'slightly improved', 'just the same' and 'worse' categories formed very similar proportions.

The replies in the three point preference scale again did not differ statistically, two-thirds of each group recording treatment 'more satisfactory' than elsewhere.

No definite conclusions can be drawn from the results of this pilot study, as the proportion of forms analysed were so unequal for the two groups, thus diminishing the validity of any comparison. It is interesting that for both out-patients and daypatients the universally expected proportion of twothirds was recovered or much improved, but this decreased slightly in respect to social and family relationships. Though not reaching statistical significance, the smaller proportion of day-patients 
doing well at work may reflect some degree of bias in selecting day-patients from those presenting with work problems. It may also be suggested that the larger number of respondents, and the significantly smaller number of spoilt or incompletely returned forms from the day-patient sample, point towards a greater involvement in, and commitment to, their past treatment, whereas for out-patients commitment may be more tenuous. Though the results may have been different had a comparable sample of out-patients responded adequately, it is doubtful whether any firm opinions could have been formulated based on such relatively crude measurements. Only a much more detailed, sophisticated investigation, designed to elicit the finer qualitative responses to the two types of approach and their meaning for the patient, can give an answer to whether, in terms of clinical and social gains (rather than in terms of management) patients are at an advantage in day care.

SUSANNE Shapar.

Day Department, Crumpsall Hospital, Manchester 8.

REFERENCES

1. Ferguson, R. S. (1968). B. med. 7., i, 119.

2. Farndale, W. A. J. (1967). New Aspects of the Mental Health Services. Oxford, Pergamon.

3. O'Gorman, G. (1968). Modern Trends in Mental Health and Subnormality. London. Butcerworth.

4. Ferguson, R. S. Personal Communication.

\section{THE LESBIAN PERSONALITY}

\section{DeAr Sir,}

In preparation for a lecture I have just re-read June Hopkins' paper (Journal, December 1969) and my suspicion that her description of personality was simply that of a lesbian who might volunteer for a survey was rekindled. The sample studied was doubly self-selected, latterly by volunteering for study and formerly by joining an active minority group. The author at one stage in her paper recognizes this, but refers on the basis of her study to the average lesbian as being independent. From the paper one could construct the hypothesis that lesbians who are the dominant partners in a relationship are more likely to join active minority groups and more likely to show the traits described in the summary of the paper. Would Sister George have allowed her Alice to volunteer for the survey or even to join a wider group of lesbians?

One does not make a sample more representative of its group by comparing it with controls. It is doubtful whether one can even describe the groups as matched for, although certain factors have been paired, the controls were presumably also volunteers who may have had entirely different motives for volunteering. There is no indication that they belong to other active minority groups. Finally, the description of the personality traits found may be those applicable to a situation in the lesbian partnership and may not be related to status in the wider world.

Highcroft Hospital,

B. H. Fookes.

\section{Erdington,}

Birmingham 23.

Dear Sir,

In the last paragraph of his letter, Dr. Fookes' comment 'One does not make a sample more representative of its group by comparing it with controls' is true. However, he then suggests that the motives of the controls were probably different from those of the subjects. I fail to comprehend the significance of such a statement. I would be very surprised to find 'the motives' of any control group in a study of this kind being queried prior to their selection as subjects. It is difficult to believe they are.

Earlier in his letter he has said, 'From the paper one could construct the hypothesis that lesbians who are the dominant partners in a relationship ... are more likely to show the traits described in the summary ... '. Dr. Fookes has obviously jumped to the conclusion that the majority of the lesbians in the investigation were the dominant partners. Such an assumption is unwarranted, if it is based on my paper. The majority of the 105 lesbians who originally participated in the research came in partner teams to be tested. The 24 selected could just as easily have been 'submissive' partners as 'dominant' ones. There is no way to distinguish, as they were selected explicitly because they most nearly matched the controls in age, intelligence and profession. In any case, I feel that strict role-typing (dominant and submissive) has no real place in the discussion of relationships generally. Roles in relationships change constantly, depending on situations, and we tend to lose sight of this fact when we stereotype the individuals concerned by placing labels on them.

My paper is open to the criticism that I have compared unmarried women with married women. My reason for doing this is that I attempted to ward off any speculation of those women claiming to be heterosexual by using facts, i.e., husband and children, as objective support of their subjective Kinsey ratings. I feared that unmarried heterosexual women might be suspect, particularly if their results (perhaps 